\title{
Unexpected death after occipital condylar fracture
}

\author{
Vincent J. Bulthuis $^{1}$ • E. M. J. Cornips ${ }^{1}$ - J. Dings ${ }^{1}$ - H. van Santbrink ${ }^{1}$ A. A. Postma ${ }^{2}$
}

Received: 24 December 2016/Accepted: 27 March 2017 /Published online: 21 April 2017

(C) The Author(s) 2017. This article is an open access publication

\begin{abstract}
We present a rare fatal complication of an occipital condylar fracture. The patient was initially neurologically intact, but showed secondary clinical deterioration. Imaging revealed extensive extra-axial hemorrhage at the craniocervical junction and an acute obstructive hydrocephalus. MR imaging demonstrated a T2 hyperintens signal in both the lower brainstem and upper cervical spinal cord, likely caused by the extra-axial hemorrhage. As prognosis was estimated infaust, supportive treatment was discontinued and the patient died soon thereafter. This case report illustrates a rare, delayed complication and unexpected death in a patient having sustained an occipital condylar fracture.
\end{abstract}

Keywords Clinical presentation $\cdot$ Complications $\cdot$ Epidural hematoma $\cdot$ Myelopathy $\cdot$ Occipital condylar fracture

\section{Introduction}

Occipital condylar fractures (OCFs) were considered quite rare, but widespread availability of modern neuro-imaging techniques has been revealing more cases in recent years. In most but not all cases, they are associated with severe craniocervical trauma such as a high speed motor vehicle accident or a fall from a substantial height [2]. The clinical presentation of OCFs is highly variable, though severe

Vincent J. Bulthuis

v.bulthuis@mumc.nl; v.bulthuis@etz.nl

1 Department of Neurosurgery, Maastricht University Medical Center, Oxfordlaan 10, 6229 EV Maastricht, The Netherlands

2 Department of Radiology, Maastricht University Medical Center, Maastricht, The Netherlands neurological deficits are more likely due to the associated neurotrauma [7]. We present a patient with an OCF and delayed neurological deterioration due to an extra-axial hemorrhage at the craniocervical junction with fatal injury to the brainstem and upper cervical spinal cord.

\section{Case description}

A 72-year-old female was admitted to the hospital after a fall down the stairs. Her medical history included diabetes mellitus, rheumatoid arthritis, and a prosthetic aortic valve. Her medication included warfarin and prednisolone. Her international normalized ratio (INR) on admittance (2.6) was corrected (1.1) with prothrombin complex concentrate and vitamin K. Her Glasgow Coma Scale score (GCS) on admission was maximal (15/15). Her main complaint was pain in the cervical and thoracic region. We did not observe any neurological symptoms or signs. We were unable to assess brain stem reflexes because of a massively swollen face; however, no swallowing disturbances and hoarseness, for example, were reported. CT scan demonstrated an Anderson and Montesano type III OCF [2] (Fig. 1), a C6 pedicle fracture, and $\mathrm{C} 7$ facet fracture on the right side, as well as fractures of the $\mathrm{T} 4$ and $\mathrm{T} 11$ vertebral bodies, the $\mathrm{T} 9$ and $\mathrm{T} 10$ transverse process on the right side, and the T8-T11 transverse processes on the left side. We did not observe any fracture near the jugular foramen or hypoglossal canal or any intracranial abnormalities.

HALO vest immobilization seemed appropriate for the OCF, but was practically impossible because of the massively swollen face. Hence, the patient was admitted to the neurosurgical ward with a rigid cervical collar. Two days after admission, she was found comatose in bed (Glasgow Coma Scale score 7/15). While we were still unable to assess brain stem reflexes, we did observe an extensor plantar response (Babinski sign) and triple response bilaterally. Emergency 


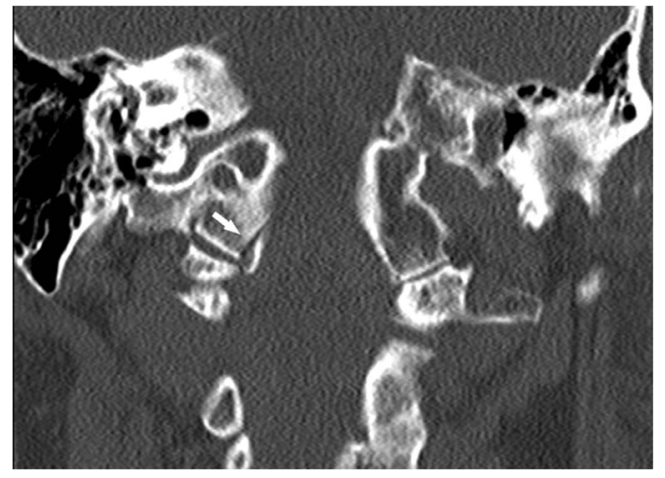

Fig. 1 Coronal CT reconstruction of the craniocervical junction demonstrating an avulsion fracture of the right occipital condyl with inferomedial displacement of the fractured fragment (white arrow). The fracture is classified as an OCF type III according to Anderson and Montensano [1]

CT scan demonstrated an extra-axial hemorrhage around the brainstem and in the posterior fossa causing an acute obstructive hydrocephalus (Fig. 2a, b). Emergency external ventricular drainage did not improve the patient's clinical condition, as her Glasgow Coma Scale score was 3/15 without any reaction
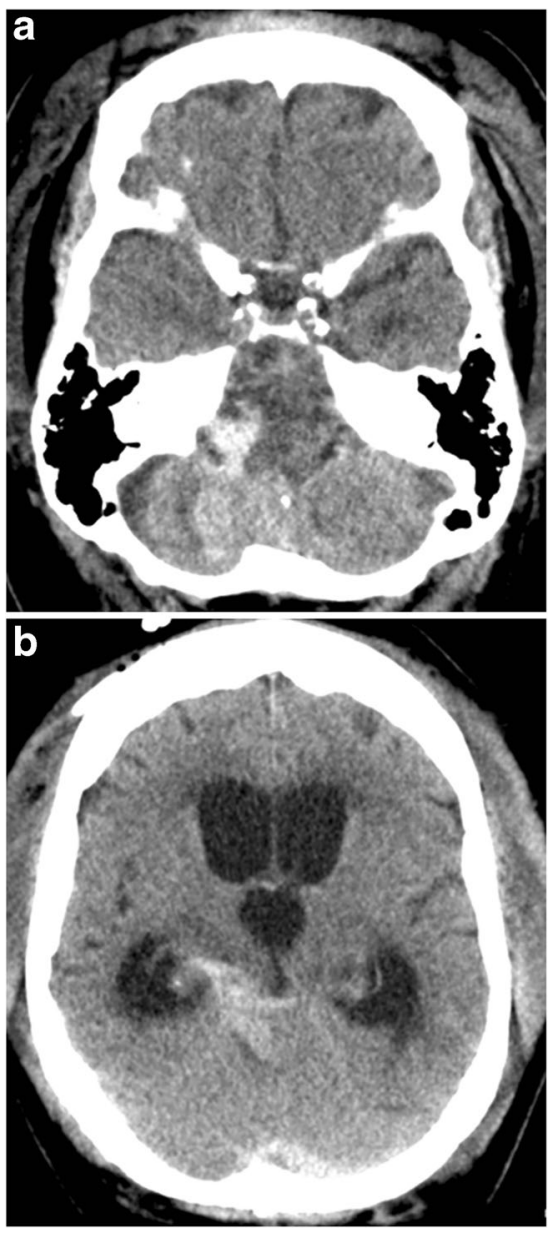

Fig. 2 a and $\mathbf{b}$ Axial CT images of the brain demonstrate an extra-axial hemorrhage around the brainstem and in the posterior fossa, causing an acute obstructive hydrocephalus to peripheral stimuli, while being unsedated and ventilated without any reaction. Next morning, MR imaging demonstrated a T2 hyperintens signal in both the lower brainstem and upper cervical spinal cord ( $\mathrm{C} 0$ to $\mathrm{C} 5$ ) likely caused by the extra-axial hemorrhage compressing the brainstem and obstructing the cerebrospinal fluid flow over the foramen magnum (Fig. 3). The observed anomalies clearly explained the patient's clinical condition, including tetraplegia and acute respiratory failure. Due to the extent of neurological damage and the duration of symptoms, prognosis was estimated infaust, and any surgical intervention was deemed futile. Supportive therapy was therefore discontinued, and the patient died soon thereafter.

\section{Discussion}

First described in 1817 by Bell [3], OCFs were considered quite rare. While their exact incidence is still unknown, they are being recognized more often because of an increased use

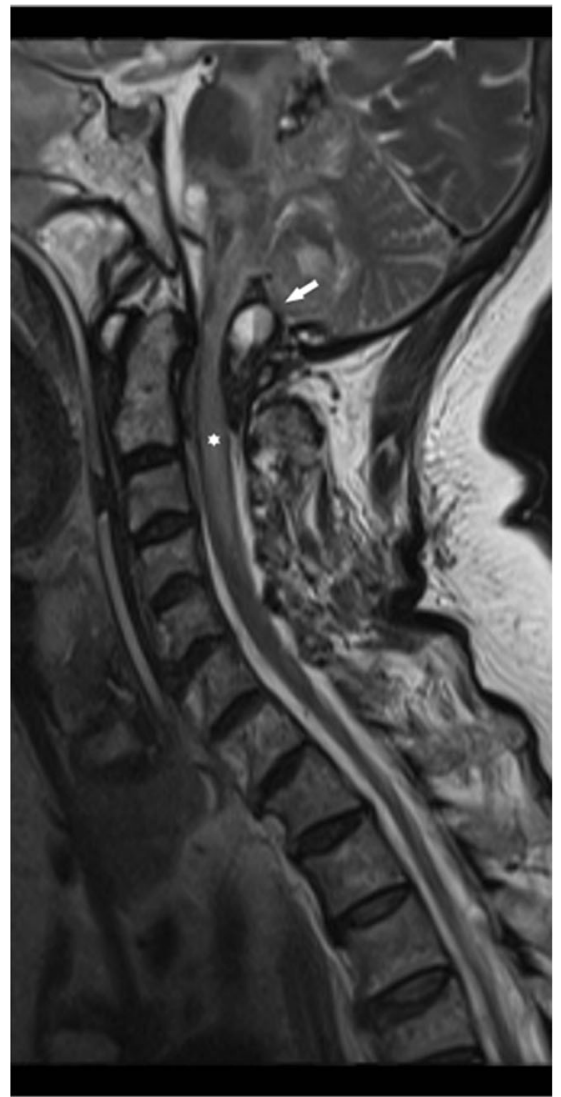

Fig. 3 Sagittal T2-weighted MR image of the cervical spine. An epidural mass with fluid level, consistent with an acute hemorrhage, is compressing the lower brain stem and upper cervical spinal cord at the level of the foramen magnum (white arrow). Additionally, hemorrhage is present at the level of the supracerebellar cistern. Note an increased signal intensity in the entire brain stem, upper cervical spinal cord (to the level of C4) (white asterisk), and cerebellum 
of CT and MR imaging [16]. To date, their incidence in severely injured trauma patients is estimated between $1 \%$ and $2 \%[7,14]$. The most widely used classification is the one by Anderson and Montesano [2] who divided OCFs into three subtypes. A type I is an impaction fracture of the occipital condyle caused by an axial loading injury. A type II is part of a more extensive skull base fracture (involving one or both occipital condyles) often caused by a direct blow to the skull. Both types are considered stable fractures [1] because of the intact alar ligaments and tectorial membrane. A type III is an avulsion fracture of the occipital condyle caused by stress on the ipsi- and contralateral alar ligaments and tectorial membrane following forceful hyperextension or hyperflexion at the craniocervical junction. It is considered a potentially unstable fracture [7].

Due to a small number of patients and a lack of prospective studies, the management of OCFs is not well established [8, 16]. Most patients with an Anderson and Montesano type I or II OCF are treated with a rigid collar, while most patients with a type III fracture are treated with a rigid collar, a HALO vest, or even surgical fixation $[4,7]$.

Even though there is substantial variability in the clinical presentation of OCFs, they always point to a serious impact to the posterior skull base and craniocervical junction. They have been associated with cranial nerve palsies (in casu the lower cranial nerves), tetraplegia, and even fatal brainstem contusion. Cranial nerve palsies are among the most frequently described injuries with an incidence as high as $31 \%$ according to some authors [15]. Nerve injury may range from an isolated cranial nerve palsy $[11,13]$ to uni- or bilateral complete 9 th through 12th cranial nerve palsies (the so-called Collet-Sicard syndrome) [5].

Despite the substantial impact necessary to fracture an occipital condyle, associated extra- or subdural hemorrhage at the craniocervical junction seems to be quite rare. In an analysis of 100 patients with 106 OCFs, merely 5 patients manifested an extra-axial hematoma on MR imaging [9]. On the other hand, in a recent review by Theodore et al., as many as 13 (22\%) of 59 patients with an OCF manifested an extra-axial hemorrhage at the craniocervical junction [14]. This discrepancy in the reported incidence of this hemorrhage may be explained by the fact that the hemorrhage may be asymptomatic. Of note, both papers do not specify the clinical course, eventual complications, and final outcome of these patients [9, 14]. Finally, three case reports illustrate the occurrence of an epidural hematoma anterior to the upper cervical spinal cord in association with an OCF [4, 6, 12]. These patients invariably suffered lower cranial nerve palsies.

Both the occurrence of hemorrhage at the craniocervical junction and lower cranial nerve palsies may be explained by the close relationship of the occipital condyle to the hypoglossal canal and jugular foramen, both of which contain an artery, a vein, and one or several cranial nerves [6]. More specifically, through the hypoglossal canal at the occipital condylar base pass the hypoglossal nerve (XIIth nerve), a meningeal branch of the ascending pharyngeal artery, and an emissary vein, while through the jugular foramen (lateral to the occipital condyle and hypoglossal canal) pass cranial nerves IX, X, and XI, the posterior meningeal artery, the inferior petrosal sinus, and the sigmoid sinus on its way to the internal jugular vein bulb $[6,8,10]$. Vascular and cranial nerve injuries in patients with an OCF are likely caused by displacement of the fractured condylar fragment in close vicinity to these fragile neurovascular structures [5]. Alternatively, venous oozing from a fractured skull base may cause increased local pressure by accumulation of fluids from the neighboring vessels due to an osmotic pressure gradient across the hematoma capsule (hygroscopic effect). The use of both warfarin and prednisolone may have contributed to the posttraumatic hemorrhage in this patient.

The secondary clinical deterioration and subsequent death of this patient may be explained by a developing myelopathy following direct compression on the lower brainstem and upper cervical spinal cord by an extradural hematoma. This irreversible damage shows the vulnerability of the craniocervical junction.

In retrospect, we could have considered performing an additional MR cerebrum and craniocervical junction following the patient's clinical deterioration to evaluate injury of the ligaments and possible local compression of the brainstem and upper cervical spinal cord. Such additional imaging might have contributed to an earlier understanding of what was actually causing the acute hydrocephalus. Of note, an early CT angiography or CT cerebrum may have given valuable information in addition to the clinical picture as well; however, both would not have been useful for a detailed assessment of the craniocervical junction.

\section{Conclusion}

An occipital condylar fracture is a potentially life-threatening condition because of the associated neurovascular damage. Symptoms may be present in the acute phase or develop in the first few days, causing dramatic clinical deterioration.

$\mathrm{CT}$, computed tomography; MR, magnetic resonance; OCF, occipital condylar fracture.

\section{Compliance with ethical standards}

Conflict of interest The authors declare that they have no conflict of interest. 
Open Access This article is distributed under the terms of the Creative Commons Attribution 4.0 International License (http:// creativecommons.org/licenses/by/4.0/), which permits unrestricted use, distribution, and reproduction in any medium, provided you give appropriate credit to the original author(s) and the source, provide a link to the Creative Commons license, and indicate if changes were made.

\section{References}

1. Alcelik I, Manik KS, Sian PS, Khoshneviszadeh SE (2006) Occipital condylar fractures. Review of the literature and case report. The Journal of bone and joint surgery British volume 88:665669

2. Anderson PA, Montesano PX (1988) Morphology and treatment of occipital condyle fractures. Spine 13:731-736

3. Bell C (1817) Surgical observations. Middlesex Hospital Journal 4: 469-470

4. De Wyngaert R, Mulkens T, Baeyaert M, Bellinck P, Salgado R, Ghijsen D, Van Dijck X, Termote JL (2006) Bilateral occipital condylar fracture with associated haematomas. Emerg Radiol 13: 79-82

5. Domenicucci M, Mancarella C, Dugoni ED, Ciappetta P, Paolo M (2015) Post-traumatic Collet-Sicard syndrome: personal observation and review of the pertinent literature with clinical, radiologic and anatomic considerations. European spine journal: official publication of the European Spine Society, the European Spinal Deformity Society, and the European Section of the Cervical Spine Research Society 24:663-670

6. Erol FS, Topsakal C, Kaplan M, Yildirim H, Ozveren MF (2007) Collet-Sicard syndrome associated with occipital condyle fracture and epidural hematoma. Yonsei Med J 48:120-123

7. Hanson JA, Deliganis AV, Baxter AB, Cohen WA, Linnau KF, Wilson AJ, Mann FA (2002) Radiologic and clinical spectrum of occipital condyle fractures: retrospective review of 107 consecutive fractures in 95 patients. AJR Am J Roentgenol 178:1261-1268
8. Leone A, Cerase A, Colosimo C, Lauro L, Puca A, Marano P (2000) Occipital condylar fractures: a review. Radiology 216: 635-644

9. Maserati MB, Stephens B, Zohny Z, Lee JY, Kanter AS, Spiro RM, Okonkwo DO (2009) Occipital condyle fractures: clinical decision rule and surgical management. Journal of neurosurgery Spine 11: 388-395

10. Matsushima K, Funaki T, Komune N, Kiyosue H, Kawashima M, Rhoton AL Jr (2015) Microsurgical anatomy of the lateral condylar vein and its clinical significance. Neurosurgery 11(Suppl 2):135145 discussion 145-136

11. Noble ER, Smoker WR (1996) The forgotten condyle: the appearance, morphology, and classification of occipital condyle fractures. AJNR Am J Neuroradiol 17:507-513

12. Oliviero A, Insola A, Santilli V, Tartaglione T, Profice P, Tonali P, Di Lazzaro V (2000) Concomitant post-traumatic craniocervical junction epidural hematoma and pontomedullary junction infarction: clinical, neurophysiologic, and neuroradiologic features. Spine 25:888-890

13. Rue M, Jecko V, Dautheribes M, Vignes JR (2013) Delayed hypoglossal nerve palsy following unnoticed occipital condyle fracture. Neuro-Chirurgie 59:221-223

14. Theodore N, Aarabi B, Dhall SS, Gelb DE, Hurlbert RJ, Rozzelle CJ, Ryken TC, Walters BC, Hadley MN (2013) Occipital condyle fractures. Neurosurgery 72(Suppl 2):106-113

15. Tuli S, Tator CH, Fehlings MG, Mackay M (1997) Occipital condyle fractures. Neurosurgery 41:368-376 discussion 376367

16. Utheim NC, Josefsen R, Nakstad PH, Solgaard T, Roise O (2015) Occipital condyle fracture and lower cranial nerve palsy after blunt head trauma - a literature review and case report. Journal of trauma management \& outcomes 9:2

The next of kin has consented to submission of this case report to the journal. 